\title{
8 \\ BUDAYA NUSANTARA MELALUI DAMAR KURUNG : Analisis Bahasa Rupa
}

\section{Ika Ismoerdjahwati}

\begin{abstract}
Abstrak
Culture is a culture of Nusantara Indonesian, which owns various cultures scattered throughout the islands, is highly variable and shifting orientation into the craft industry. In contemporary culture, the culture industry has experienced 'globalization. So some of the work of cultural products, which could not be untouched by globalization, becoming increasingly marginalized and not recognized, even then becoming more and more lost. Prior to all of that, then comes the initiative to conduct a study of the works of cultural products fared thus, among others, lanterns Damarkurung of Gresik, by Masmundari (late) . Research using qualitative research paradigm constructivist. Through this research is expected to gain an understanding of the images contained on the rounded wall paper lanterns, its origin, its artists, and its supporting environment. The conclusion is, the pictures turned out to have the intent and purpose, as well as the old concept of how the reading of the temples in East Java, which is used to guide how to draw and how to tell the images that surround the lantern.
\end{abstract}

Keywords: culture, Nusantara, lanterns, Damarkurung

\section{PENDAHULUAN}

Indonesia merupakan Negara kepulauan dengan ragam suku dan etnik, yang bertebaran di seluruh tanah air. Melalui ragam budaya nasional yang dimiliki, terdapat banyak kesenian etnik yang akhirnya dapat mendunia karena kegigihan bangsa kita memperkenalkan budaya keseniannya sampai ke manca negara. Budaya yang berasal dari beragam etnik ini kemudian mengalami pergeseran orientasi, yang menurut Koentjaraningrat, (1994)

“...mengalami perubahan yang terjadi di semua cabang kesenian, tak hanya kesenian modern yang berubah, juga pada kesenian tradisional yang semakin dinamis. Hal ini terjadi karena adanya pergeseran nilai budaya ke orientasi industri”.

Tidak banyak yang bisa dipahami oleh sebagian besar dari kita, bahwa orientasi berpikir masyarakat masa kini berubah karena peradaban yang juga menyertainya. Era industri sudah sedemikian meng 'gobal', sehingga budaya yang mendasarpun dalam kehidupan keseharian manusia, yakni kehidupan ritual untuk keperluan acara keagamaanpun juga sudah menjadi bagian dari industri. Mulai dari tata cara upacara agama, perlengkapan pernak-pernik upacara, hingga perlengkapan busana dan asesories para pelaksana upacara. Berikut, tata bunyi, tata ruang, tata gerak, hingga tata krama juga bisa dijadikan komoditi pasar industri yang pada perkembangannya, kemudian dikenal sebagai bagian dari industri kreatif. Semua sudah menjadi bagian dari Industri. Budaya industri sudah merupakan kebutuhan hidup keseharian dari masyarakat, oleh karena itu perlunya pemahaman adanya budaya urban yang memiliki fluktuasi tinggi dalam 
mobilitasnya.

Karena budaya urban masa kini sangat bergantung pada alam dan budayanya dan hubungannya dengan budaya leluhur yang pernah sangat kuat pada masa lampau, yang sebenarnya mengalami kontinuitas. Oleh karena itu 'krisis' sosial sering terjadi, yang kesemuanya itu disebabkan karena pemahaman pada diri sendiri dan alam serta budayanya mengalami distingsi (perbedaan arti), atau mereka menciptakan distingsi antara alam dan budaya, sehingga terciptalah realitas yang sifatnya 'alami', sehingga alam yang mengalami distingsi (perubahan makna) menjadi 'alam' yang alami, yang merupakan hasil produk budaya. Misalnya, bunyi air yang menetes di dedaunan, menjadi inspirasi untuk peniruan bunyi air menetes pada peralatan bunyi-bunyian yang diciptakan masyarakat sesuai dengan budayanya.

Budaya dalam arti yang sebenarnya, adalah merupakan sebuah proses pemahaman yang bukan hanya memahami alam atau realitas eksternal melainkan juga sistem sosial yang merupakan bagian dari identitas sosial itu sendiri, serta kegiatan keseharian orang-orang yang berada dalam sistem tersebut.

Seharusnya, kita sebagai pribadi, sangat penting mengenal diri kita sendiri, relasi sosial kita dan kondisi nyata yang dihasilkan oleh proses kultural secara bersamaan. Itulah sebabnya, sebenarnya budaya selalu berlaku kontinuitas. Transformasi konseptual antara alam dan budaya menjadi proses teknik berkreasi para seniman atau para kreator dalam melengkapi kebutuhan fungsi maupun manfaat untuk mempermudah hidupnya dalam mencapai upaya kebutuhan yang lebih lengkap.

Sehingga melalui pola kontinuitas, kepunahan produk suatu budaya tidak segera terkikis habis, sebab 'alam' budaya akan selalu menyesuaikan diri dengan realitas eksternal dan sosial budaya masing-masing generasi yang mewakili peradabannya

Pada perkembangan budaya yang berasal dari khasanah Nusantara yang berkembang pada masa kini, tentang budaya ke Nusantaraan telah mengalami berbagai perubahan kultural. Hal ini disebabkan karena terjadinya pola hidup fluktuasi yang tinggi dari budaya urban, yang sebenarnya sudah ada sejak budaya asing masuk ke kawasan Nusantara, melalui pola akulturasi dan inkulturasi. Sehingga hasil produk budaya, mengalami reduksi makna dan bentuk, malahan ada juga yang mengalami transformasi makna dan bentuk, karena adanya penyesuaian budaya yang mewakili peradabannya.

\section{DAMARKURUNG: PENING- GALAN BUDAYA DARI GRESIK, JAWA TIMUR}

Damarkurung adalah hasil produk budaya yang berasal dari kabupaten Gresik, Jawa Timur. Damarkurung, sebenarnya berupa lampion yang memiliki motif-motif khas yang unik, dan motif-motif ini semula, hanya dianggap sebagai sejenis gambar anak-anak, tetapi senimannya adalah seorang ibu berusia lanjut, bernama

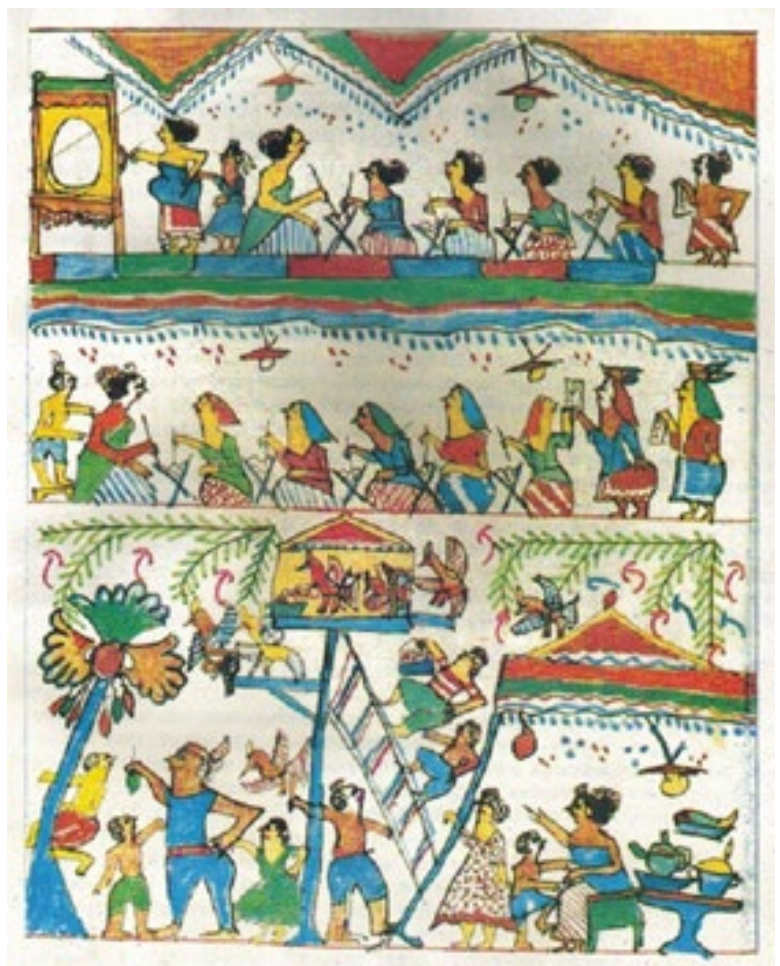

Gambar 1.

Motif hias Damarkurung pada salah satu bentuk gambar dinding. Sumber: ISMOERDJAHWATI, 2009. 
Masmundari. Motif-motif inilah yang kemudian menjadi kajian penelitian, dengan menggunakan paradigma konstruktivis yang berorientasi pada metode kualitatif.

Artinya,

Motif-motif tersebut, memang menimbulkan pertanyaan yang mendasar, ragam seni hias Damarkurung memiliki arti dan bercerita tentang sesuatu yang sangat ingin diketahui, dan dipelajari, karena seni hias tersebut tidak hanya sekedar gambar yang mirip dengan gambar anak-anak, dan senimannya yang sudah berusia lanjut, tetapi masih eksis dengan karya-karyanya. Ada kemungkinan dalam diri senimannya tersimpan sejarah yang sangat panjang.

\section{SEJARAH LAMPION YANG BER- MOTIF HIAS DAMARKURUNG SEBAGAI HASIL PRODUK TRA- DISI}

Karya seni tradisi di beberapa lingkungan kultur Indonesia, dalam bentuk wujudnya umpamanya, adalah tercipta secara anonim, menjangkau satu wilayah terbatas, tidak banyak mengalami perkembangan, dan benar-benar merupakan refleksi dari satu kebudayaan kehidupan masyarakat tradisional. Sehingga karya seni rupa tradisi adalah merupakan bentuk karya seni rupa 'fungsional' terhadap masyarakat pendukungnya. Sebab, karya seni rupa tradisi, merupakan karya seni rupa yang mempunyai fungsi untuk memberikan rasa aman, terlindung, dan merasa kuat, disamping untuk pemenuhan hidup keseharian. Demikian juga dengan ungkapan seni rupanya, 'indahnya' suatu karya seni rupa tradisi, bukan sekedar memuaskan mata, api juga melebur dengan kaidah adat, tabu, kepercayaan, agama dan sebagainya. Juga dapat dijelaskan, bahwa masyarakat Indonesia, merupakan masyarakat kepulauan. Dalam satu tulisan dari Primadi TABRani dari bukunya 'Belajar dari sejarah dan ligkungan';

“...manusia kepulauan daerah pengem- baraannya daerah pengembaraannya seluas Samudra Hindia dan Pasifik, ia memillih menetap... muncullah suku, lokasi, daerah yang manusianya memiliki kemampuan untuk memadukan sesuatu yang datang dari luar dengan apa yang telah dimiliki hingga berkembanglah kebudayaan tanpa kehilangan jati diri. Mucullah keunikan masing-masing suku/daerah/pulau yang tidak statis, tai cepat atau lambat terus berkembang dengn masuknya unsur baru dari luar. Bersamaan dengan itu rasa kekeluargaan sebagai anak cucu dari nenek moyang yang sama, persaudaraan sesama mnusia kepulauan sebagai manusia bahari, memunculkan Wawasan $\mathrm{Nu}-$ santara yang bercorak Bhinneka Tunggal Ika”.

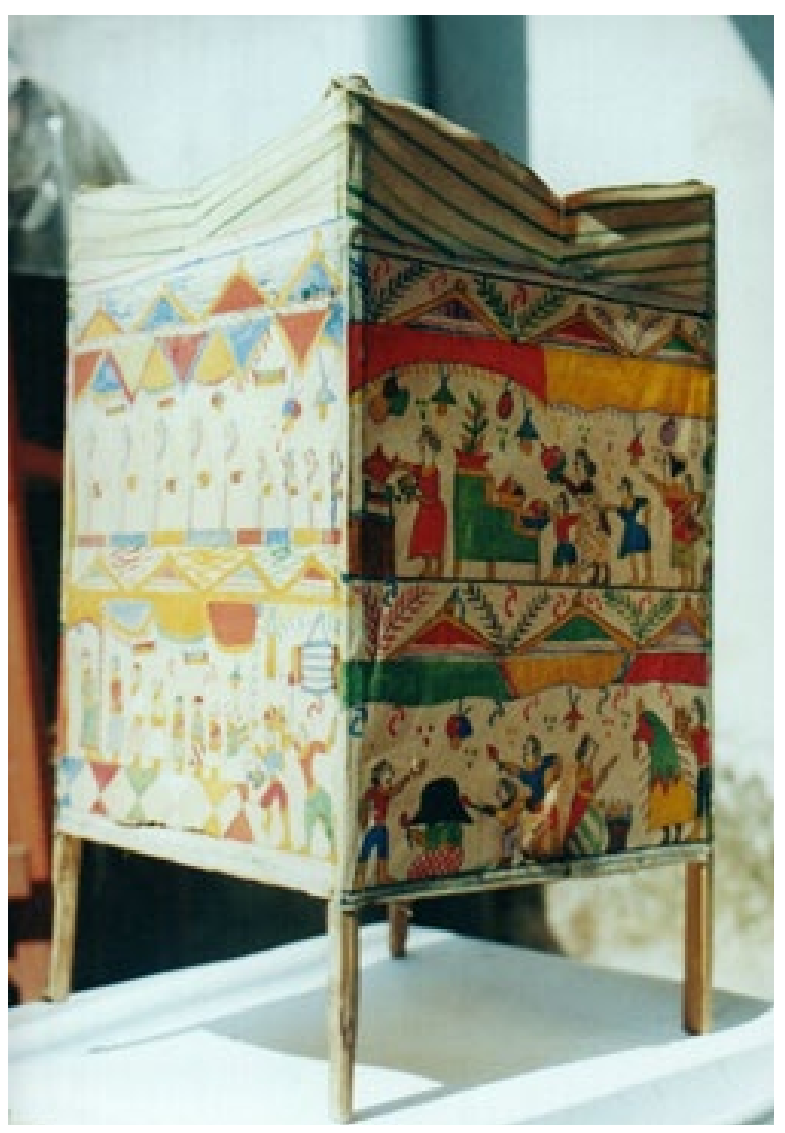

Gambar 2.

Motif hias Damarkurung, pada lampion. Pada perkembangannya, lampion yang bergambar motif hias tersebut, dikenal sebagai lampion Damarkurung. Sumber: ISMOERDJAHWATI, 2009 
Akhirnya dari pernyataan tersebut dapat diartikan bahwa budaya Nusantara memiliki aneka ragam kebiasaan tradisi berupa kekaryaan yang beraneka ragam jenis, fungsi, kegunaan, bahan dan media. Kemudian terdapat perbedaan tapi hampir mirip satu karya antara etnis satu dengan yang lain, malahan terdapat kesamaan konsep meskipun berbeda istilah saja. Misalnya, di beberapa daerah memiliki tradisi lampion hias, tetapi tidak banyak yang menggunakan gambar-gambar, apalagi gambar-gambar bercerita sebagai hiasan lampion semacam Damarkurung.

Pada umumnya adalah, lampion yang berhiaskan kertas warna-warni atau berhiaskan mozaik. Pada beberapa daerah, terdapat juga lampion dengan gambar-gambar, tetapi biasanya juga hanya sebagai penghias ornamen saja. Pada lampion Damarkurung (lihat gambar 2), terdapat beberapa keunikan, yang tidak terdapat pada jenis lampion hias yang lain, yakni :

1. Bentuk ragam hiasnya yang menggambarkan rangkaian obyek yang bercerita;

2. Kemudian pada tiap lampion terdapat gambar-gambar yang ternyata masing-masing gambar memiliki kisahnya sendiri-sendiri;

3. Selain gambar- gambar tersebut digunakan untuk menghiasi lampion, ternyata pada perkembangannya juga digunakan pula pada gambar-gambar dinding dengan menggunakan media kertas ( lihat gambar 1).

Kemudian, yang istimewa lagi adalah, bahwa menurut MASMUNDARI (alm) untuk menceritakan kisah-kisahnya, menggunakan cara yang tidak lazim, yakni dengan memutarnya dari kiri ke kanan atau dari kanan ke kiri, berdasarkan gambar yang dianggap sakral olehnya. Gambar yang dianggap sakral adalah gambar-gambar dengan akivitas; sholat Iedul Fitri, pengajian, ikan duyung, lelang bandeng, pertunjukan 'Raja Mina, syukuran.

Sedangkan gambar-gambar yang dianggap profan, adalah gambar-gambar dengan aktivitas; kegiatan sehari-hari, kegiatan di pasar, keramaian pasar malam (terdapat kegiatan permainan anak-anak disini (IsmoerdjAHWATI, 2009: 114). Pada gambar-gambar yang dianggap profan, cara berceritanya dengan memulai gambar dari mana saja, dan memutar lampionnya dari kanan ke kiri, agar supaya cerita yang disampaikan bisa 'berjalan'.

Bila lampion diputar dari kiri ke kanan dengan 'patokan' gambar yang dianggap sakral, maka secara otomatis, dimulai dari gambar tersebut, lampion mulai diputar dari kiri - ke kanan, sehingga aspek berceritanya bisa jalan. Hal ini mengingatkan kita tentang konsep pembacaan candi-candi yang berada di Jawa Timur umum-

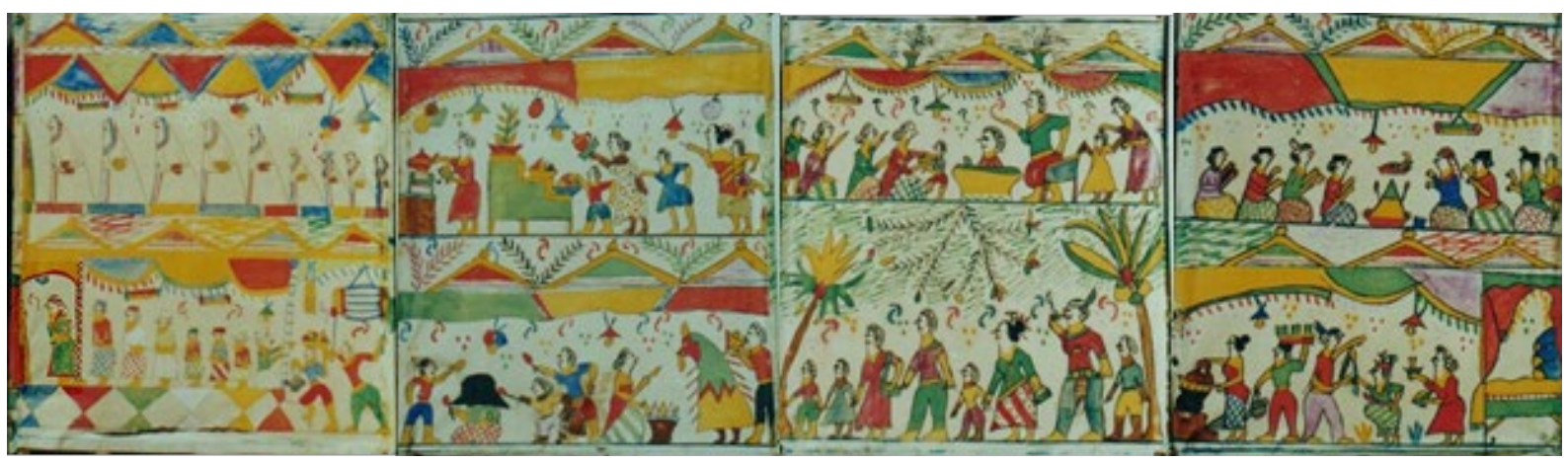

Gambar 3.

Lampion yang memiliki empat sisi dibuka. Cara mengamati dan menceritakan peristiwa pada lampion ini, terdapat kisah-kisah bergambar dengan memutarnya dari kiri ke kanan, dimulai dengan gambar yang dianggap sakral, yakni sholat bersama di acara ledul Fitri, hal ini mengingatkan pada tata cara mengitari candi- candi prasawya di Jawa Timur. Sumber: ISMOERDJAHWATI, 2009 
Tabel Analisis

Motif hias Damarkurung pada salah satu bentuk gambar dinding. Sumber: ISMOERDJAHWATI, 2002.

\begin{tabular}{|c|c|c|}
\hline GAMBAR LAMPION & BAGAN & ANALISIS \\
\hline & $\begin{array}{l}\text { Lampion Data A, } \\
\text { sekuen atas dan } \\
\text { sekuen bawah., } \\
\text { merupakan cerita } \\
\text { sakral, terdapat isi } \\
\text { wimba orang- } \\
\text { orang sholat } \\
\text { beriamaah. }\end{array}$ & $\begin{array}{l}\text { Cerita sekuen lampion Data A, sebenarnya dipilih berdasarkan pilihan bebas, dan di- } \\
\text { gunakan sebagai permulaan analisis. Terdapat isi wimba para manusia pada sekuen atas } \\
\text { dan bawah yang merupakan jenis cerita sakral dengan cara wimba arah lihat berkejaran. } \\
\text { Pada sekuen atas, isi wimbanya mengenakan mukena yang menunjukkan para jemaah } \\
\text { wanita. Pada sekuen bawah yang paling kiri mengenakan jubah, sebagai imam masjid, } \\
\text { sedangkan yang lainnya mengenakan peci dan sarung, yang menunjukkan para jemaah } \\
\text { pria. Kecuali pada sekuen bawah terdapat dua orang di sebelah kanan yang bertugas } \\
\text { memukul bedug dan seorang lagi menyiapkan sesajian Terdapat atap pada sekuen atas } \\
\text { dan bawah. Pada Data A sekuen atas dan bawah ini menggambarkan suasana sholat } \\
\text { berjamaah di suatu masjid yang sama/berbeda-beda. }\end{array}$ \\
\hline & $\begin{array}{l}\text { Lampion Data B } \\
\text { sekuen bawah } \\
\text { dan sekuen atas } \\
\text { merupakan } \\
\text { merupakan cerita } \\
\text { profan, terdapat } \\
\text { isi wimba kegiatan } \\
\text { sehari-hari. }\end{array}$ & $\begin{array}{l}\text { Lampion Data B, merupakan urutan cerita selanjutnya, dengan arah mengirikan gambar } \\
\text { (prasawya), yang artinya lampion diputar ke kiri, berarrti jenis ceritanya profan, krena isi } \\
\text { gambarnya merupakan peristiwa sehari-hari. Sehingga, untuk melihat gambarnya un- } \\
\text { tuk bercerita dari bawah ke atas. Sequen bawah, isi wimbanya (gambarnya) merupakan } \\
\text { serangkaian kegiatan, dengan arah lihat berhadapan, dan bisa dimulai dari mana saja. } \\
\text { Dengan pengambilan gambar tembus pandang, yang artinya dalam bahasa rupa dikenal } \\
\text { dengan sebtan pengambilan gambar sinar X. Agar supaya kejadian di dalam ruangan } \\
\text { (ditandai dengan gambar-gambar atap), dapat diceritakan kembali. }\end{array}$ \\
\hline & $\begin{array}{l}\text { Lampion Data C, } \\
\text { Sekuen bawah } \\
\text { dan sekuen atas, } \\
\text { merupakan cerita } \\
\text { profan Terdapat } \\
\text { isi wimba orang- } \\
\text { orang bepergian }\end{array}$ & $\begin{array}{l}\text { Lampion data } C \text { merupakan sekuen berikutnya. Lampion data } C \text { terdiri dari sekuen } \\
\text { bawah dan sekuen atas. Sekuen bawah isi wimbanya merupakan serombongan orang } \\
\text { yang pergi dari suatu tempat. Semua menghadap dari kanan ke kiri, dengan arah lihat } \\
\text { berkejaran. Terdapat garis-garis spiral yang menggambarkan waktu yang sudah gelap. } \\
\text { Dua buah pohon mengampit rombongan ini, satu diujung kiri, dan satu lagi diujung } \\
\text { kanan. Titik-titik dan tanda panah terdapat pula disekuen ini. Sekuen ini menggam- } \\
\text { barkan suasana perjalanan serombongan orang yang pergi dari suatu tempat.Sekuen } \\
\text { atas, isi wimbanya merupakan orang-orang yang melakukan suatu kegiatan dengan arah } \\
\text { lihat berhadapan, dan sudut pengambilan sinar X, karena terdapat atap disepanjang } \\
\text { sekuen ini. Pada atap disepanjang sekuen ini, terdapat tanaman pot dan garis spiral } \\
\text { yang menunjukkan adanya ruang dan waktu, yang sudah cukup gelap berikut titik-tit- } \\
\text { ik dan tanda panah. Sekuen ini menggambarkan suasana kesibukan di rumah salon } \\
\text { kecantikan, dengan para tamu yang terdiri dari ibu-ibu yang sedang menunggu giliran } \\
\text { pelayanan salon tersebut. }\end{array}$ \\
\hline & $\begin{array}{l}\text { Lampion Data D, } \\
\text { Sekuen atas dan } \\
\text { sekuen bawah, } \\
\text { merupakan cerita } \\
\text { sakral, karena isi } \\
\text { wimba orang- } \\
\text { orang syukuran. } \\
\text { Sekuen bawah kesi- } \\
\text { bukan di dapur. }\end{array}$ & $\begin{array}{l}\text { Data D merupakan sekuen terakhir dari rangkaian cerita dari lampion tersebut. Kare- } \\
\text { na terdapat isi wimba orang-orang syukuran maka cerita ini jenis cerita sakral. Tentu } \\
\text { saja untuk berceritanya dimulai dari sekuen atas. Sekuen atas isi wimbanya merupakan } \\
\text { orang-orang yang sedang melakukan hajat syukuran. Dengan arah lihat berhadapan, } \\
\text { posisi tumpeng di tengah. Sudut pengambilan dengan sinar X, karena terdapat atap } \\
\text { disepanjang sekuen ini. Disebelah kanan tumpeng ada orang yang mengenakan sor- } \\
\text { ban. Dibelakang sebelah kanan terdapat seorang anak memanjat punggung ayahnya } \\
\text { yang khusuk bedoa kelompok ini menghadap ke kiri. Tamu-tamu juga khusuk berdoa } \\
\text { menghadap ke kanan. } \\
\text { Sekuen bawah isi wimbanya beberapa orang yang sedang melakukan kegiatan, ada ibu } \\
\text { yang membawakan sesuatu untuk ibi hamil yang sedang sibuk berdandan kekduanya } \\
\text { menghadap ke kiri. Jadi arah lihatnya berhadapan dan sudut pengambilannya sinar X, } \\
\text { terdapat titik-titik dan tanda panah. }\end{array}$ \\
\hline
\end{tabular}


nya menggunakan konsep pembacaan yang berputar dari kiri ke kanan yakni prasawya (berkah dari atas turun ke bawah). Misalnya, candi Singhasari di kabupaten Singasari, lalu candi Kidal di Kabupaten Malang, candi Penataran di kabupaten Blitar, semuanya berada di wilayah Jawa Timur. Berbeda dengan candi-candi yang berada di wilayah Jawa Tengah yang menggunakan konsep pembacaan pradaksina (menuju ke kesucian diri), artinya menggunakan pembacaan yang berputar dari kanan - ke kiri.

\section{ANALISI BAHASA RUPA}

Analisis isi pada lampion Damarkurung, sebelumnya sudah disusun dalam buku yang sudah diterbitkan oleh Dewan Kesenian Jawa Timur pada tahun 2009, dengan judul Damar Kurung dari Masa ke Masa. Di dalam tulisan jurnal ini, analisis isi pada lampion Damarkurung hanya sebatas pada salah satu lampion kertas yang sudah ada dari tahun 1970, dan lampion ini yang berhasil ditemukan sejauh yang masih dapat ditelusuri jejaknya (lihat Tabel Analisis)

\section{KESIMPULAN}

Pada masyarakat budaya Nusantara terdapat persamaan gagasan dalam konsep kekaryaan, terjadinya perbedaan bukan untuk dipertentangkan tetapi diselaraskan, sehigga dianggap menjadi lebih sempurna. Dalam hal, lampion Damarkurung yang merupakan produk budaya masyarakat pesisir, ternyata sudah sangat tua usia dalam penggarapan konsepnya, seumur dengan penggarapan candi-candi yang terdapat di Jawa Timur. Masmundari (alm) hanya meneruskan budaya leluhur yang sudah dijalani secara turun-temurun dalam bentuk gambar-gambar yang bergaya masa kini sesuai dengan jaman Masmundari (alm) hidup. Tetapi konsep kuno Indonesia masih hidup melalui cara Masmundari menggambar dan menceritakan ulang gambar-gambar yang dibuatnya. Tidak banyak warga yang mengenali jenis gambar dan metodanya.
Oleh karena itu, generasi kemudian, banyak yang tidak memahami dan tidak mengerti akan kebiasaan menggambar almarhumah, sehingga kebiasaan tersebut putus, dan tidak terhubung lagi. Melalui penelitian ini, rahasia masa lalu tentang budaya gambar masyarakat leluhur, dapat terungkap melalui lampion Damarkurung, dan senimannya Masmundari (alm).

\section{DAFTAR PUSTAKA}

Abdullah M. Amin.

1996. Warisan Spiritualitas Islam di Jawa: Dari Spiritual ke Moralitas. Dalam Rub Islam dalam Budaya, Aneka Budaya Bangsa, Aneka Budaya di Jawa. Jilid II. Jakarta: Yayasan Festifal Istiqlal.

Agus Sunandar

1999 Analisis Perkembangan Ungkapan Rupa Bentuk Dan Hiasan Perahu Tradisional Madura. Tesis tidak diterbitkan. Bidang Khusus Seni Murni. Program Pascasarjana, Magister Seni Rupa dan Desain, Institut Teknologi Bandung.

AMINUDDIN.

1999. Paradigma Konstruktivitas Dalam Penelitian Tradisi Lisan Sunan Giri di Gresik Jawa Timur. Dalam WARTA ATL. Jurnal Pengetahuan dan Komunikasi Peneliti dan Pemerhati Tradisi Lisan. Edisi V/Juni/1999.

AMIN, DARORI.

2000. Sinkretisme dalam Masyarakat Jawa'. Dalam Islam dan Kebudayaan Jawa. Darori Amin (Edz). Yogyakarta: Gama Media.

Anshari, ENDANG S.

1991. Estetika Islami. Nilai dan Kaidah Asasi Islami Tentang Seni (Sebuah Telaab Pendabuluan). Makalah Utama Sessi, Estetika Islam dan Permasalahan Kesenian Masa Kini dan Esok. Jakarta, 21-24 Oktober 1991. Festifal Istiglal.

Arnold, Thomas W.

1985 Painting in Islam. A Study of pictorial Art in Muslim Culture. With A New Introduction. By B.W. Robinson. New York: Dover Publication, Inc. 
Beardsley, Monroe C.

1979 On The Creation of Art'. Part II. Artistic Creativity. Dalam Art and Philosophy Reading in Aesthetics. W.E. Kennick (Ed). Second Edition. Amherst College. St. Martin's Press-New York

Budiharto, Dwi.

1999. Relief Candi Tigawangi dan Surawana: Tinjauan Cara Wimba dan Tata Ungkapannya. Tesis. Bidang Studi Seni Murni. Tidak diterbitkan. Program Seni Rupa dan Desain. Fakultas Seni Rupa Dan Desain. Institut Teknologi Bandung.

Denzin, K. Norman, dan Yvonna S. LinCOLN.

1994. Introduction Entering the Field of Qualitatif Research dalam Handbook of Qualitatif Research. Norman K. Denzin dan Yvonne S. Lincoln (Ed). Thousand Oak: Sage Publication.

Dewey, John.

1934. Art as Experience. Minton, Balch \& Company, New York.

DhARSONO.

1999. Seni Lukis Wayang Indonesia Dekade 1990-an. Sebuah Pendekatan secara Holistik.Tesis. Tidak diterbitkan. Program Magister Seni Rupa dan Desain. Program Pascasarjana ITB.

Djauhari, KH. Moh. Tidjani.

1996 Peran Islam Dalam Pembentukan Etos Masyarakat Madura'dalam. Rub Islam dalam Budaya Bangsa. Aneka Budaya di Jawa. Jilid II. Jakarta: Yayasan Festifal Istiglal.

Eliade, Mircea.

1958 Pattern in Comparative Religion. Translated by Rosemary Sheed. A Meridian Book. New American Library. Times Mirror. (Ed Rev. 1963, 1974)

Greertz, Clifford.

1973 The Interpretation of Culture. Basic Books. Inc., Publisher, NY.

GrAFF, H.J.DE, DAN Th.G.TH. Pigeaud.

1985. Kajian Sejarah Politik Abad ke 15 dan 16'. Dalam Kerajaan-Kerajaan Islam
Pertama di Jawa. Seri terjemahan Javanologi. Hasil kerjasama Proyek Penelitian dan Pengkajian Kebudayaan Nusantara, dengan Perwakilan Koninklijk voot Taal-, Landen Volkunkunde. Terj. Bahasa Indonesia: Grafitipers dan KITLV, Leiden. Jakarta: Grafitipers.

Hamdy SALAD.

2000 Agama Seni. Refleksi Teologis dalam Ruang Estetika. Yogyakarta: Semesta.

Harun Hadiwijono.

1983 Manusia dalam Kebatinan Jawa. Jakarta: Sinar Harapan.

HARYANTO, S.

1988 Pratiwibawa Adbilubung. Sejarah dan Pekembangan Wayang. Jakarta: Penerbit Djambatan.

HaRYANTO, S

1991 Seni Kriya Wayang Kulit, Seni Rupa, Tatahan dan Sunggingan. Jakarta: Pustaka Utama Grafiti.

ISMURDYAHWATI, IKA.

2009 Damarkurung dari Masa ke Masa. Surabaya: Dewan Kesenian Jawa Timur.

Hasyim Munif.

1995 Pioner dan Pendekar Syiar Islam Tanah Jawa. Riwayat Ringkas Syeb Maulana Malik Ibrabim dan Kanjeng Sunan Giri Sultan Ainul Yaqin. Yayasan Abdi Putra Al-Muhaimin.

Hauser, Arnold.

1985 The Sosiologi of Art. Translated by Kenneth J. Northcot. The University Of Chicago Press.

Hildawati Soemantri.

1998 Introduction. Indonesia: The Art of the Archipelago'. Dalam Indonesia Heritage. Vol. 7 Visual Art. Singapure: Archipelago Press.

Holm, BiLl.

1973 Northwest Coast Indian Art An Analysis of Form. University of Washington Press. Seattle and London. 
Holt, Claire.

2000 (1967). Melacak Jejak Perkembangan Seni di Indonesia. Terj. R.M. Soedarsono. Arti Line: Masyarakat Seni Pertunjukan Indonesia.

Soemardjo, JacoB

2000. Filsafat Seni Bandung: Penerbit ITB.

TABRAni, PRIMADI.

1995. Belajar dari Sejarah dan Lingkungan. Sebuah renungan mengenai wawasan kebangsaan dan dampak globalisasi. Bandung: Penerbit ITB.

TABRAni, PRimadi.

1998. Message from Ancient Walls. Bandung: Penerbit ITB.

TABRAni, PRIMADI.

1999. Menggali Konsep Kria Tradisi Untuk Keunggulan Seni Rupa Masa Depan. Proceding Konperensi Tahun Kria dan Rekayasa. Bandung, 26 Nopember 1999, ITB. 